\title{
An unusual case of rudimentary parotid gland with distended stensen's duct
}

\author{
K Mubeen ${ }^{1}$, VR Jigna ${ }^{2}$, K Ranganath ${ }^{3}$, B Manjunath ${ }^{4}$ \\ ${ }^{1}$ Professor and Head of Department, Department of Oral Medicine and Radiology, Government Dental College \& Research \\ Institute, Bangalore, India. \\ ${ }^{2}$ Post graduate student, Department of Oral Medicine and Radiology, Government Dental College \& Research Institute, Bangalo- \\ re, India. \\ ${ }^{3}$ Consultant Radiologist, Ragavs Diagnostics and Research Centre, Bangalore, India. \\ ${ }^{4}$ Professor, Department of Oral and Maxillofacial Surgery, Aecs Maruthi College of Dental Sciences, Bangalore, India.
}

Correspondence:

Dr. Jigna VR,

\#902, Block II, Jains Prakruthi,

Kanakpura Road,

Jayanagar 7th Block,

Bangalore 560070

India.

E-mail: jigna.vr@gmail.com

\author{
Mubeen K, Jigna VR, Ranganath K, Manjunath B. An unusual case of \\ rudimentary parotid gland with distended stensen's duct. J Clin Exp Dent. \\ 2010;2(2): e85-7.
}

http://www.medicinaoral.com/odo/volumenes/v2i2/jcedv2i2p85.pdf



\begin{abstract}
Congenital absence or rudiment major salivary glands, especially of the parotid glands, are a rare entity. Aplasia of parotid glands has been described alone or in association with abnormalities of other salivary glands, first branchial arch developmental disturbances and other congenital anomalies such as lacrimoauriculodentodigital syndrome, mandibulofacial dysostosis and ectodermal dysplasia. Absence is most commonly unilateral, and may be associated with accessory or rudimentary glandular tissue. There are several reported cases of isolated patulous Stensen's duct causing air insufflations in the glands and recurrent parotid gland enlargement. However, in the literature there is no reported case of association of rudimentary parotid gland with a patulous Stensen's duct. This paper aims at reporting an interesting and unusual presentation of unilateral imperfectly developed parotid gland with a distended Stensen's duct in a five year old mentally challenged girl who presented with an unintentional habit of blowing out cheeks several times in a day resulting in air insufflations and recurrent parotid swelling.
\end{abstract}

Key words: Parotid gland, rudimentary, Stensen's duct, patulous. 


\section{Introduction}

Parotid gland is the largest salivary gland which secretes its saliva through the Stensen's duct into the oral cavity. The parotid glands are the first to develop at roughly around 6 weeks in utero followed by submandibular and sublingual salivary glands (1). An unknown disturbance in this process can result in a rare presentation of aplasia or rudiment salivary glands. Parotid gland agenesis has been commonly reported in conjunction with several congenital conditions like lacrimoauriculodentodigital syndrome, mandibulofacial dysostosis and ectodermal dysplasia, cleft palate, Treacher Collins syndrome and anophthalmia. Hypoplasia of the parotid gland has been associated with Melkersson-Rosenthal syndrome and developmental malformations of the ductal systems have been related with branchial cleft abnormalities (2-5). However, description of isolated cases of such presentation is scarce in the literature. We report a case of unilateral rudimentary parotid gland with patulous Stensen's duct causing insufflation of air through the duct resulting in recurrent parotid swelling in a 5 year old female patient.

\section{Case Report}

The parents of a five year old mentally challenged female patient reported to us with a painless recurrent swelling of the right middle third of the child's face noticed since 3 months. Patient had a habit of unintentional blowing of the cheeks many times in the day. On clinical examination a diffuse swelling was noted in the right pre auricular area which on palpation revealed crepitation. Intraoral examination showed exudation of frothy mucous saliva from the right Stensen's duct (Fig. 1). A provisional diagnosis of pneumoparotid was made.

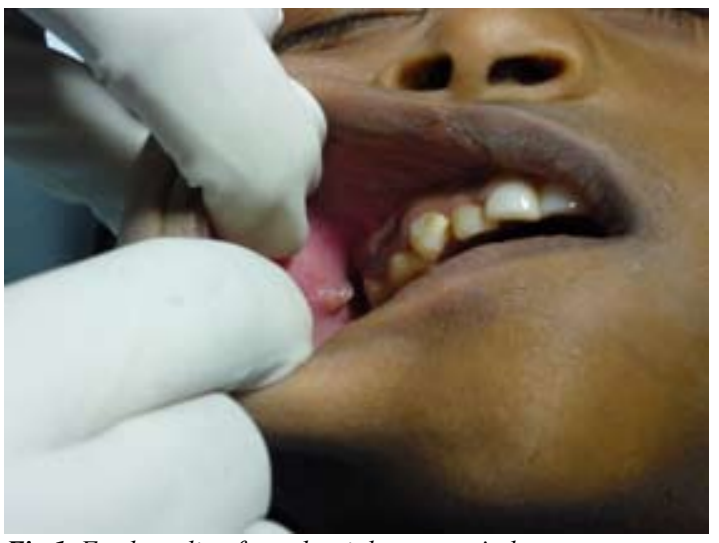

Fig 1. Frothy saliva from the right stenson's duct.

An ultrasonographic examination of the parotid glands reveled air in patulous Stensen's duct of the right parotid gland. Computed tomography (CT) images of the region showed a circumscribed irregularly curvilinear pocket of air hypointensity extending on to the superficial components of the right parotid gland and small pockets of similar hypointensities within the parenchymal compo- nents of the gland (Fig.2).

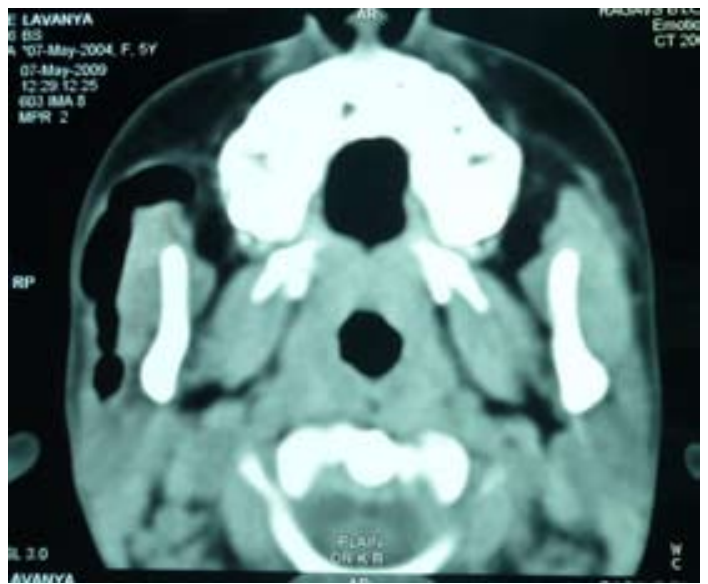

Fig 2. CT showing the circumscribed irregularly curvilinear pocket of air hypointensity extending on to the superficial components of the right parotid gland and small pockets of similar hypointensities within the parenchymal components of the gland.

The sialogram and three-dimensional (3D) CT images (Fig. 3) revealed incomplete formation of right parotid gland and no breach in the parotid capsule.

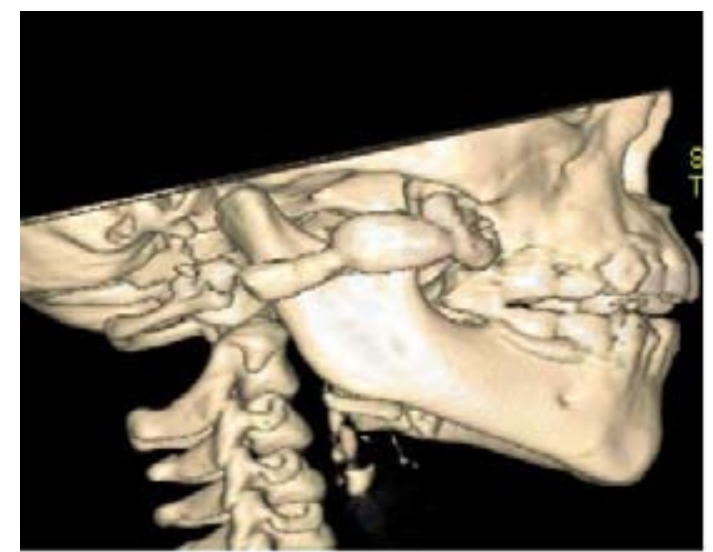

Fig. 3. 3D CT showing incompletely formed (Rudimentary) right parotid gland.

With these findings, a diagnosis of rudimentary parotid gland with patulous Stensen's duct was made. The rudimentary parotid resulted in space around the gland and the patulous duct resulted in air insufulation into the space. Considering the age of the patient, delayed milestones and possible complications of surgery, no intervention was planned. Patient was advised for a regular follow up review.

\section{Discussion}

The salivary glands arise as buds from the epithelial lining of the oral cavity between 4 and 8 weeks in utero. These primordial buds grow and extend into the underlying mesenchymal tissue as a solid core of cells to form cords, terminus of each branch being a rounded, 
radial array of cells. Later, as these cords become canalized, they form ducts, and the terminal cells differentiate into acini. The glands are divided into lobules by the surrounding mesenchyme, which also envelopes them to form a capsule. The parotid glands appear during the fourth week of gestation in the angle between the maxillary process and the mandibular arch (1).

In 1879, a first case of parotid aplasia with resultant absence of saliva was described by Bradbury (2), following which number of cases of agenesis of salivary glands has been reported (3-6). In 1949, Kabakov (7) described congenital absence of both parotid glands and undevelopment of the remaining salivary glands. Unusual cases of unilateral or bilateral parotid aplasia with accessory parotid tissue has also been described (8-11). The exact etiology and pathogenesis of aplasia or hypoplasia of salivary glands has not been established, however is likely due to arrest in organogenesis (12). The patients with salivary gland aplasia may be asymptomatic or may complain of dry mouth, have difficulty in chewing and swallowing, and have an increased incidence of dental caries, due to reduction of the protective effect of saliva in the oral cavity. In cases of rudimentary parotid gland as in our case, the saliva is produced but the quality and quantity are compromised.

A number of case reports of patulous Stensen's duct have been recorded in the past (13-15). In these cases, air insuffulates into the parotid gland due to increased intraoral pressure and results in recurrent parotid swelling. This is commonly seen as an occupational hazard among glass blowers and wind instrument players. It may also be iatrogenic due to damage to the duct during dental procedures or self induced among pediatric patients to gain attention or avoid school. In our case, the child unintentionally blew her cheeks 50-100 times in a day leading to increased intraoral pressure. As the right Stensen's duct was patulous and large, air insufflations occurred resulting in a recurrent parotid swelling. However, this air cavity was noted superficial and anterior to parotid tissue rather than within it, which may be explained to be because of air entrapment in the space between the rudimentary parotid gland and surrounding tissue which was supposed to be occupied by the normal parotid gland.

Surgical excision of the rudimentary gland and patulous Stensen's duct ligation could have prevented the recurrent swelling in the parotid region. However, it would not have been without complications like inadequate saliva resulting in dry mouth, swallowing difficulties and dental caries. Parotid surgeries are also associated with complications due to facial nerve injury leading to decrease in facial muscle activity. Stensen's duct transposition to tonsillar fossa was not considered in this patient because of intricacies of surgery and cost factors.

In view of the child's age, there is a possibility of the development of parotid tissue in the later years owing to the growth potential and hence only close long term follow up of the patient is validated. Light massage of the area, warm compresses, prophylactic antibiotics and anti inflammatory medications were prescribed for the patient.

Cases with unusual presentations always remain a challenge for diagnosis and adequate management. In the reported case, diagnosis could be well established with the clinical findings and different imaging modalities. However, management remains a challenge due to systemic compromises and possible complications. We intend to document the long term follow up of the case and report in the future.

\section{References}

1. Johns ME. The salivary glands: anatomy and embryology. Otolaryngol Clin North Am. 1977;10:261-71.

2. Bradbury EP. Absence of saliva. Boston Med Surg J. 1879;100:342.

3. Flusser J, Zitka M, Chvojkova V. Aplasia of the salivary glands.Cas Lek Cesk. 1949;88:772-4.

4. Nayak UV. Anomalies in the Development of Salivary Glands. J Anat. 1927;61:261-2.

5. McDonald FG, Mantas J, McEwen CG, Ferguson MM. Salivary gland aplasia: an ectodermal disorder? J Oral Pathol. 1986;15:115-7.

6 . Whyte AM, Hayward MW. Agenesis of the salivary glands: a report of two cases. Br J Radiol. 1989;62:1023-6.

7. Kabakov BD. Congenital absence of both parotid glands and undevelopment of the salivary glands. Vestn Khir Im I I Grek. 1949;69:42. 8. Bhide VN, Warshawsky RJ. Agenesis of the parotid gland: association with ipsilateral accessory parotid tissue. AJR Am J Roentgenol. 1998;170:1670-1.

9. Goldenberg D, Flax-Goldenberg R, Joachims HZ, Peled N. Misplaced parotid glands: bilateral agenesis of parotid glands associated with bilateral accessory parotid tissue. J Laryngol Otol. 2000;114:883-5.

10. Antoniades DZ, Markopoulos AK, Deligianni E, Andreadis D. Bilateral aplasia of parotid glands correlated with accessory parotid tissue. J Laryngol Otol. 2006;120:327-9.

11. Higley MJ, Walkiewicz TW, Miller JH, Curran JG, Towbin RB. Aplasia of the parotid glands with accessory parotid tissue. Pediatr Radiol. 2009 Nov 25.

12.Kubo S, Abe K, Ureshino T, Oka M. Aplasia of the submandibular gland. A case report. J Craniomaxillofac Surg. 1990;18:119-21.

13. Mandel L, Kaynar A, Wazen J. Pneumoparotid: a case report. Oral Surg Oral Med Oral Pathol. 1991;72:22-4.

14. Martín-Granizo R, Herrera M, García-González D, Mas A. Pneumoparotid in childhood: report of two cases. J Oral Maxillofac Surg. 1999;57:1468-71.

15. Luaces R, Ferreras J, Patiño B, Garcia-Rozado A, Vázquez I, López-Cedrún JL. Pneumoparotid: a case report and review of the literature. J Oral Maxillofac Surg. 2008;66:362-5. 